\title{
COSMOPOLITAN BERLIN? INTERPRETING THE LINGUISTIC LANDSCAPE OF A COSMOPOLITAN CITY
}

\author{
LENA BUDARINA
}

\section{Introduction}

Since the fall of the Berlin Wall in 1989, Berlin's reputation as a multicultural cosmopolitan city has steadily grown. Nowadays Berlin is one of the most populous urban areas in Europe, with around 3.5 million inhabitants from over 180 nations. In recent years such places, where people of many ethnicities, religions and cultures meet and live in close proximity, has caught the attention of researchers from various fields of knowledge. Urban space, created by people living there, turns from 'an architectonic creation' into an important source of information, a dialog, a public communication. Thus, linguists consider a cosmopolitan city as a multilingual urban space, where a lot of language processes can be observed. A concept, which connects urban space, its 'language' and 'communicators' is termed as linguistic landscape (LL).

The aim of this study is to show that LL can provide valuable insight into the linguistic situation of Berlin. This will be done by analysing the data collected from specific public domains such as street signs, advertising signs, billboards, shop signs, informative signs etc. in Berlin. Signs in public areas accessible to everyone can mirror a particular language background. It is true especially for bi- and multilingual cities, where sings serve as a useful tool to find out more about the functions these different languages fulfill within specific contexts.

Furthermore, we need to ask a question if languages displayed on signs truly reflect the demographic structure of the city or if there are other more common languages? Can languages brought by migrants survive and develop in a cosmopolitan environment or just stay 'invisible' for other inhabitants of cosmopolis? 


\section{Linguistic landscape as a reflection of the linguistic diversity}

The study of language on signs in public space is a relatively new field in sociolinguistics, developing at a very high speed since 1997, when Landry and Bourhis's initial study 'Linguistic landscape and ethnolinguistic vitality' was published. Since then numerous scientists from over the world have discovered the enormous potential of this young discipline, which can give answer to multiple questions about language and society and also give insight into a linguistic situation in a particular place.

Despite the fact that the term linguistic landscape research was first used in 1997, the study of public signage goes back further in the history, in the 70s of the 20th century (Backhaus, 2007). Canadian researchers Rodrigue Landry and Richard Bourhis (1997: 25) were the first authors who defined the term linguistic landscape clearly: 'The language of public road, signs, advertising boards, street names, place names, commercial shop signs, and public signs on government buildings combines to form the linguistic landscape of a given territory, region or urban agglomeration'. In other words, the linguistic landscape consists of all visual forms of language presented in the public space of a certain geographic area. Later this therm has been applied to the concept and has already entered common usage in scientific circles (Backhaus, 2005; Ben-Rafael and Shohamy, 2006; Cenoz and Gorter, 2006; Huebner, 2006).

The linguistic landscape studies demonstrate that it is possible to gain insight into the social, political, historical and cultural composition of a multilingual community by systematic observation and descriptive analysis of literacy in the public sphere. The LL contains concrete manifestations of language choice, status, mediations of culture and knowledge. This public, visual text paints a real picture of the everyday linguistic interactions and social realities that define a community, providing physical evidence of language usage and frequency - often a more accurate description than information gathered and reported in official census and demographic documents.

Thus, it is not surprising, that multilingual societies and communities have become the object of interest of many researchers in the recent years. The studies of LL cover different multilingual areas all over the world, including Tokyo (Backhaus, P. 2006), Quebec (Landry and Bourhis, 1997), Israel (Ben-Rafael et al., 2006; Spolsky and Cooper, 1991), the Basque country (Cenoz and Gorter, 2006), London (Grześkowiak, 2010) etc. In Poland this topic is mostly developed by such scholars as Stanisław Puppel (Puppel, 2007) and Marta Grześkowiak (Grześkowiak, 2010) from the Department of Ecocommunication at Adam Mickiewicz University in Poznan.

Most of the linguistic landscape research has focused on present-day analysis of the graphic environment. Pavlenko suggests that LL 'is not a state but a diachronic process' (Pavlenko, 2010). The contemporary LL, she argues, cannot be fully understood without examining how it developed and came about. Spolsky and Cooper (1991), who examined historical references on street signs in Jerusalem, reveal the role that changing political regimes play in shaping linguistic landscapes. 
The LL indicates the degree of linguistic diversity in a certain area. A choice of bilingual or multilingual signage indicates a multilingual situation. The dominance of a specific language in the LL shows the power and status of a majority or strong minority group over other groups. For example, the high-status language used in official domains is more likely to be found on public signs than the languages of lower status. Ben-Rafael et al. (2006: 27) write that the 'LL analysis allows us to point out patterns representing different ways in which people, groups, associations, institutions and government agencies cope with the game of symbols within a complex reality".

As was mentioned above, the linguistic landscape refers to linguistic objects that mark the public space. LL marks space in specific ways, as 'belonging' to certain population group. Linguistic landscape research can lead to various conclusions about speech community and its social and political implications, about prevailing cultural beliefs. Moreover, it mirrors different social issues.

This paper explores how these signs reflect the dynamics of political, economic and social transformations and demonstrate a linguistic diversity and the co-existence of languages in a cosmopolitan city.

\section{Berlin: some demographic characteristics}

Berlin is a German city and a federal state, situated in the heart of Europe. It has been the capital city since 1991, and is the largest city in the country. Since the vanishing of the borders between Central and Eastern European countries and the subsequent liberalisation of travel restrictions, the number of people immigrating to Germany has been increasing. The statistics released in the Migration Report 2013 compiled by Germany's Federal Office for Migration and Refugees and approved by the Federal Cabinet on 21 January 2015 shows that 1.23 million persons moved to Germany in 2013, the highest influx in 17 years ${ }^{1}$. As a result, Germany became one of the largest immigration countries in the world and Berlin, as a capital, became a cosmopolis. Expectedly it has an impact on the city linguistic landscape.

Nowadays Berlin is well-known as a multi-national, cosmopolitan city. According to The statistical office of Berlin and Brandenburg (Amt für Statistik BerlinBrandenburg), in December 2013, 538,729 Berlin's residents (15.3\% of the population) were of foreign nationality, originating from over 180 different countries. Another estimated 460,000 citizens in 2013 are descendants of international migrants and have either become naturalised German citizens or obtained citizenship by virtue of birth in Germany. In 2008, about $25-30 \%$ of the population was of foreign origin. ${ }^{2}$

\footnotetext{
${ }^{1}$ http://www.euractiv.com/sections/global-europe/berlin-reacts-germanys-2013-record- immigrationnumbers-311464

${ }^{2}$ https://www.statistik-berlin-brandenburg.de/pms/2011/11-02-04.pdf
} 
In Berlin there are more than 25 non-indigenous communities with a population of at least 10,000 people, including Turkish, Polish, Russian, Lebanese, Palestinian, Serbian, Italian, Bosnian, Vietnamese, American, Romanian, Bulgarian, Chinese, Austrian, Ghanaian, Ukrainian, French, British, Spanish, Israeli, Thai, Iranian, Egyptian and Syrian communities. Official language in Berlin (as in Germany) is Standard German, which is by law the medium of spoken and written communication virtually in all public sectors of society. The most-commonly-spoken foreign languages in Berlin are Turkish, English, Russian, Arabic, Polish, Kurdish, Vietnamese, Serbian, Croatian and French. ${ }^{3}$

\section{Studying the linguistic landscape of Berlin: methodology}

The observations presented in this article are part of a larger study on the linguistic landscape of Berlin that focuses on the relationship between demographic data and the frequency of different languages visible on displays of written language in two districts of the city. Research is based on a case study of the linguistic landscape of two different parts of Berlin: shopping and entertainment area in the City Centre (which includes Potsdamer Platz Square, Sony Centre, Quarter Potsdamer Platz and the streets surrounding it) and district Charlottenburg-Wilmersdorf (area that covers the western city centre of Berlin and the adjacent affluent suburbs). These areas were chosen to contrast the LL in the central shopping areas with other local neighbourhood areas.

Potsdamer Platz began as a trading post where several country roads converged just outside Berlin's old customs wall. Nowadays this area is the heart of a metropolis with new skyscrapers, numerous shops, restaurants, theatres and cinemas. There are always a lot of tourists here. Charlottenburg-Wilmersdorf district is completely different. As of 2010, the borough had a population of 319,628, of whom about $110,000(34 \%)$ were of non-German origin. The largest ethnic minorities were Turks at 4\%; Poles at 3.5\%; Arabs, former Yugoslavians and Afro-Germans at $2.5 \%$ each; Russians at $1.5 \%$; and Ukrainians and Iranians at $1.0 \%$ each. ${ }^{4}$ Such multinational area can be a perfect example of linguistic diversity and co-existence of languages in a cosmopolitan city.

A common method in LL research is to photograph the signs, count the number of occurrences of each language variety. Digital pictures were taken in August 2015 .

\footnotetext{
${ }^{3}$ https://www.statistik-berlin-brandenburg.de/english/documents.asp

${ }^{4}$ http://www.statistik-berlin-brandenburg.de/Publikationen/Stat_Berichte/2011/SB_A1-5_hj01-11_ BE.pdf
} 
The first stage was counting and classification all of the fixed signs visible in the street or in the shop windows. A 'sign' was qualified as 'any piece of written text within a spatially definable frame' (Backhaus, 2006: 55). A total of 368 signs were counted and classified according to the language(s) used (Table 1).

Table 1. Overview of all languages displayed in all of the signs in two areas of Berlin

\begin{tabular}{|l|c|c|}
\hline \multicolumn{1}{|c|}{ Languages } & Number of signs & $\%$ \\
\hline German only & 134 & 36.5 \\
\hline German + English & 94 & 25.5 \\
\hline English only & 68 & 18.5 \\
\hline Turkish only & 7 & 2 \\
\hline Russian only & 6 & 1.5 \\
\hline Chinese only & 4 & 1 \\
\hline $\begin{array}{l}\text { Others (French, Spanish, Polish, Serbian, Arabic, Thai, Vietnamese, } \\
\text { Ukrainian) }\end{array}$ & 14 & 4 \\
\hline English + Chinese & 6 & 1.5 \\
\hline $\begin{array}{l}\text { German + other (Turkish, Chinese, French, Spanish, Polish, Serbian, } \\
\text { Arabic, Thai, Vietnamese, Ukrainian) }\end{array}$ & 35 & 9.5 \\
\hline Total & & 100 \\
\hline
\end{tabular}

Apart from monolingual and bilingual signs, during the analysis multilingual signs were found as well (Picture 1, Picture 2).

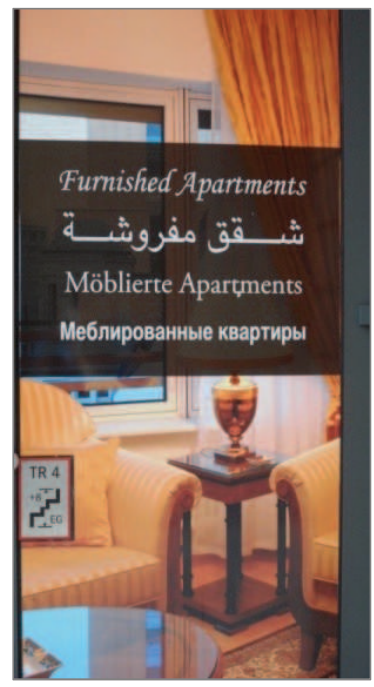

Picture 1. Multilingual sign in Berlin (City Centre) 


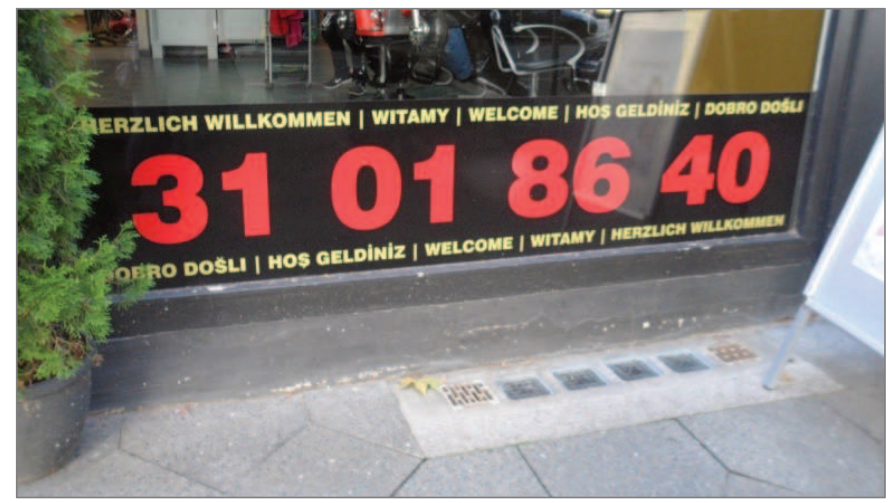

Picture 2. Multilingual sign in Berlin (Charlottenburg-Wilmersdorf)

During the analysis of data collected in two different areas we noticed, that languages displayed on these areas are different too. In the shopping and entertainment area at the City Centre, surprisingly, we did not find any non-German monolingual sign. Instead of that $93 \%$ of all signs were presented only German, only English or German and English at the same time (Table 2).

Table 2. Overview of all languages displayed in all of the signs in the City Centre of Berlin

\begin{tabular}{|l|c|c|}
\hline \multicolumn{1}{|c|}{ Languages } & Number of signs & $\%$ \\
\hline German only & 68 & 40 \\
\hline German + English & 54 & 32 \\
\hline English only & 36 & 21 \\
\hline German + other (French, Spanish, Arabic) & 14 & 7 \\
\hline Total & 172 & 100 \\
\hline
\end{tabular}

In Charlottenburg-Wilmersdorf we noticed that on $70.5 \%$ of total signs we can see German or English. At the same time Turkish, Russian and Chinese are less visible, but there are monolingual signs in these languages. Other languages (French, Spanish, Polish, Serbian, Arabic, Thai, Vietnamese, Ukrainian) were displayed only a few times and only on bilingual or multilingual signs (Table 3 ).

Considering the total number of signs that displays the use of each of the languages found in the LL of these areas (i.e. on both monolingual and multilingual signs), we can see that German appeared on around half of the all signs (Table 4). Nearly 1/3 of all signs contained English. Chinese, Turkish and Russian figured only marginally in the LL of the researched areas. Other languages (French, Spanish, Polish, Serbian, Arabic, Vietnamese, Thai, Ukrainian) were found only at $4 \%$ of all signs. 
Table 3. Overview of all languages displayed in all of the signs in Charlottenburg-Wilmersdorf

\begin{tabular}{|l|c|c|}
\hline \multicolumn{1}{|c|}{ Languages } & Number of signs & $\%$ \\
\hline German only & 66 & 34 \\
\hline German + English & 40 & 20 \\
\hline English only & 32 & 16.5 \\
\hline Turkish only & 7 & 3.5 \\
\hline Russian only & 6 & 3 \\
\hline Chinese only & 4 & 2 \\
\hline $\begin{array}{l}\text { Others (French, Spanish, Polish, Serbian, Arabic, Thai, Vietnamese, } \\
\text { Ukrainian) }\end{array}$ & 14 & 7 \\
\hline English + Chinese & 6 & 3 \\
\hline $\begin{array}{l}\text { German + other (Turkish, Chinese, French, Spanish, Polish, Serbian, } \\
\text { Arabic, Thai, Vietnamese, Ukrainian) }\end{array}$ & 21 & 11 \\
\hline Total & 196 & 100 \\
\hline
\end{tabular}

Table 4. Percentage of signs on which each language appears

\begin{tabular}{|l|c|}
\hline \multicolumn{1}{|c|}{ Language } & $\%$ \\
\hline German & 55 \\
\hline English & 35 \\
\hline Chinese & 2.5 \\
\hline Turkish & 2 \\
\hline Russian & 1.5 \\
\hline Other (French, Spanish, Polish, Serbian, Arabic, Vietnamese, Thai, Ukrainian) & 4 \\
\hline
\end{tabular}

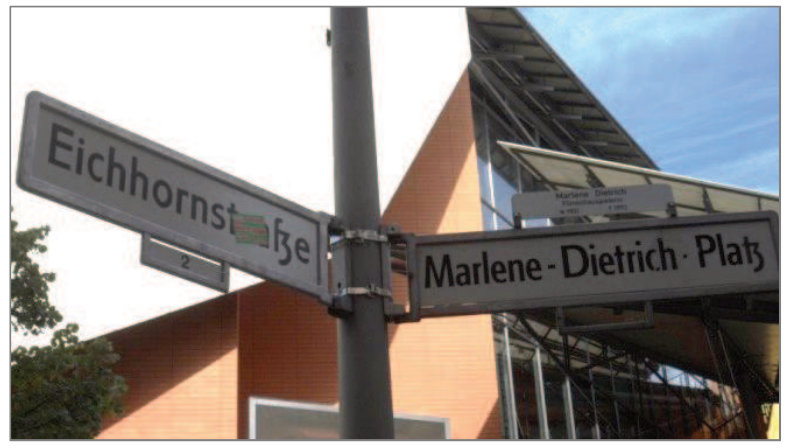

Picture 3. ‘Top-down' sign in Berlin

The next step of data analysis is a comparison between 'official' (e.g. road signs, street names) and 'unofficial' signs (e.g. shop signs, advertisements, graffiti) according to their producers (Backhaus, 2006). It is frequently assumed that official signs 
are produced by governmental authorities, hence alternatively termed 'top-down' in Ben-Rafael et al.'s (2006) study of the linguistic landscape of Israel, and that unofficial signs are made by individual social actors in private sectors, hence 'bottom-up'. Our data collection shows that in Berlin the most 'top-down' signs are in German only (street names, prohibition signs, emergency instructions, place names) (Picture 3) or in German and in English (parking instructions, bike rental etc.), whereas in 'bottom-up' signs other languages than German are used (primarily English).

Considering 'top-down' signs in Berlin, produced by governmental authorities, it is important to notice that buying a ticket for public transport in the ticket machine, we have an option to choose a language (Picture 4). The same option we have visiting Berlin's official website (www.berlin.de): we can choose one of the eight languages (German, English, French, Italian, Chinese, Polish, Russian, and Turkish).

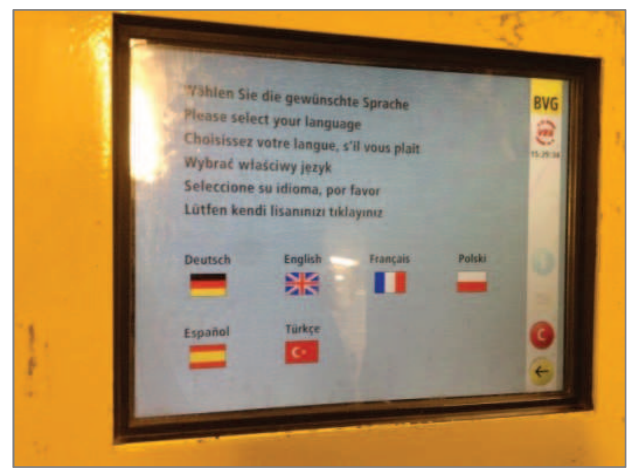

Picture 4. Screen of the ticket machine in Berlin

Referring to demographic characteristics of Berlin, we expected to see more languages in public signs. Despite being the most-commonly-spoken foreign languages in Berlin, Turkish, Russian, Polish, Arabic were 'visible' only at about $10 \%$ of all signs, whereas English as a language of globalisation was presented at $42 \%$ of all signs.

\section{English language in the linguistic landscape of Berlin}

Berlin like other capital cities has its own language policy that aims and preserving the unique national heritage: language and culture. However, nowadays the process of globalisation affects the development of every European country. That is why the role of English in the linguistic landscape development is becoming increasingly important. 
One of the main themes in previous LL research has been the spread of English as a global language and its relation to other regional and local linguistic varieties. All over the world researchers have observed the increased use and visibility of the English language in public spaces (Backhaus, 2007; Ben-Rafael et al., 2006; Shohamy, 2009; Grześkowiak, 2010). In most cases, English signs do not index a local community of speakers of the language; the phenomenon has been interpreted 'as a symbolic expression [...] to join the English language community and to associate with the values that are typically attached to it (American/Western culture, internationalisation, etc.)' (Backhaus, 2007: 63). Such artificial languages are thus seen as a reflection of globalisation in process (Gorter, 2006).

Data collection of different type of signs in Berlin shows that the English language becomes an integral part of Berlin's linguistic landscape and is widely used at universal brand names, product names and company names. It is not difficult to explain this fact. All the shops and businesses in research areas may potentially cater to a non-German speaking client, that is why shop owners would wish to target these clients in a language they might understand. As in many parts of the world, English is the obvious choice for the lingua franca, therefore producers of commercial signs try to use English.
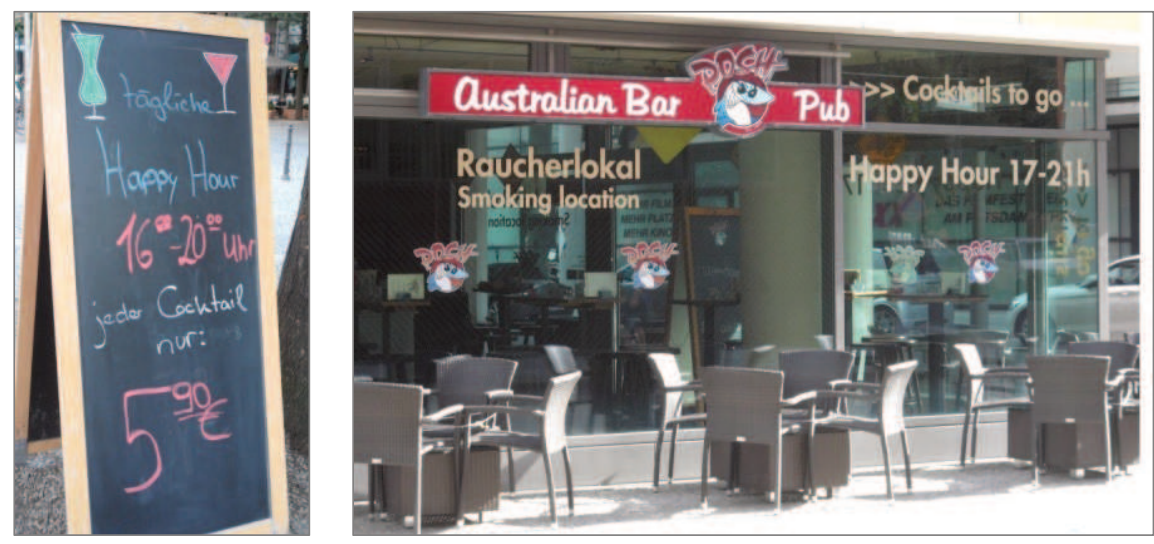

Picture 5. Restaurants in Berlin

A lot of restaurants are named in English, whereas special day offers outside the restaurant are written by hand in German. At the city centre restaurants mostly have a menu in different languages for tourists (in English, Spanish, Italian, French, Japanese). There are a lot of bilingual signs (German + English) with popular English phrases such as: happy hour, today's specials, season sale, coffee to go, open air etc. (Picture 5). 
Typical examples of bilingual signs in both German and English were fairly frequent and displayed by upmarket shops or travel agencies. At CharlottenburgWilmersdorf there are a lot of restaurants and shops, where we can see non-German bilingual signs (Picture 6).

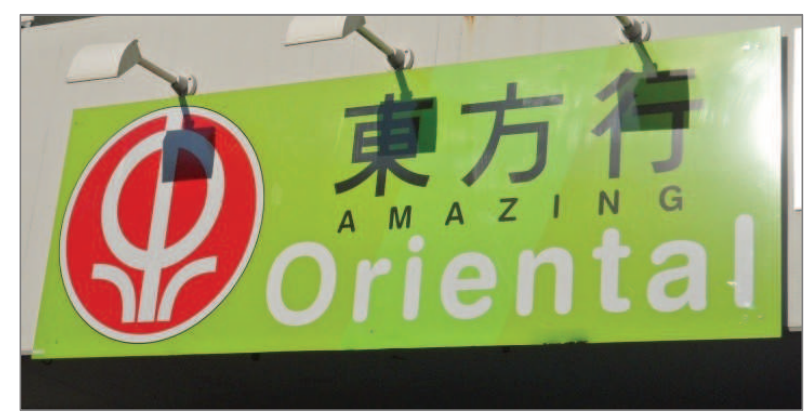

Picture 6. Bilingual sign in Berlin

Most of beauty salons and nail studios are also named in English (Picture 7). German can be found only on lists of services or working hours. The majority of signs with English observed in Berlin was monolingual and bilingual (German + English).
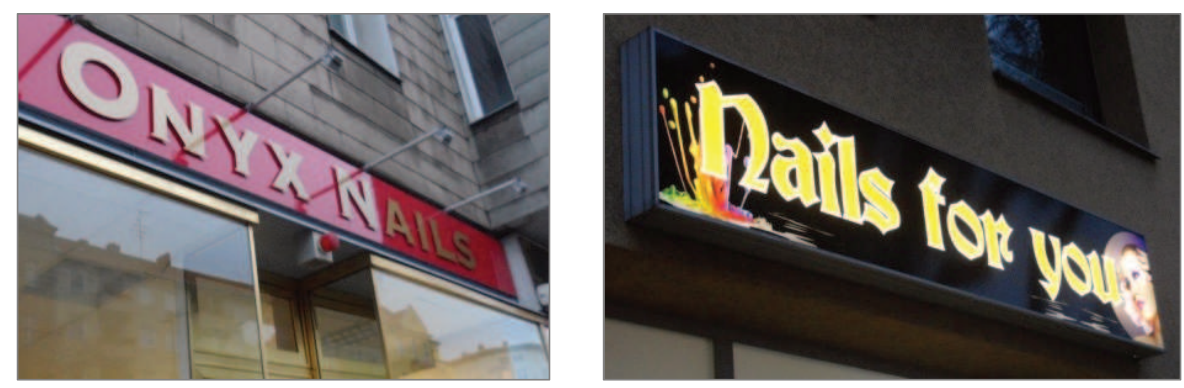

Picture 7. Nail studios in Charlottenburg-Wilmersdorf

In the era of globalisation commitment to the native language and culture can hardly compete with the necessity to enter the world of international communication and, thus, the need to maintain a productive dialogue with the help of the global language. The use of English in advertising, trade, business and everyday life in Berlin is unavoidable and can be explained by the necessity to meet the requirements and expectations of the target audience, especially that of the young generation. 


\section{Concluding remarks}

The representation of different languages in multilingual urban environments is a phenomenon that has emerged in research of linguistic landscape in the recent years (Ben-Rafael et al., 2006; Ben-Rafael, 2009; Cenoz and Gorter, 2006). This study of linguistic landscape of Berlin has shown, that different signs are not only used to sell specific goods and services, they give us information about how the area is marketed and sold to tourists, businesses, new residents and investors.

The names of shops and services constitute a vast part of the linguistic landscape of an area, mainly the City Centre as most shops are located there. In the modern globalised world, signage of shops is linguistically colourful. World languages appeared in shop names with English in the first place and the application of foreign words in the signage is internationally an increasingly popular phenomenon.

The observation of signs in two different parts of the German capital led to interesting results. Considering our examples, we could mention that Berlin is moving towards being a cosmopolis (about 32\% of all signs are non-German, about 35\% of signs are bi- or multilingual), where German is the primary language of communication and English functions as a local lingua franca. This is a result of economic activities and globalisation. Unfortunately, our research did not reveal a strong presence of other foreign languages in a public area in spite of the presence of large international communities in the city. When visiting Berlin we can hear, but not always 'see' foreign languages apart from English, especially at the City Centre.

There are a lot of migrants in Berlin. They come to a cosmopolitan city with their language and culture. While living there foreigners become a part of cosmopolis. They learn German and English to be a 'Berliner', feel more confident and have more job opportunities. Thus, their own languages tend to stay only spoken amongst particular minority and remain 'invisible', with any 'power' in a cosmopolitan city. English, on the other hand, is the language of symbolic power in Berlin, which means Berlin's growing success as a tourist destination. In this case the importance of the use of English may be regarded as tourist friendly and therefore beneficial to the economy. English is widely viewed as the principal international language despite the fact that it has no official status.

In future research to avoid the risk of being one-sided during interpretations of signs, it could be reasonable to combine an analysis of signs with interviews with sign producers. The main aim of the interviews is to understand the meanings of logos, names and images. Furthermore, we might discuss with locals and tourists about their understanding of signs.

As was mentioned above, this study is a part of a larger research of LL in a cosmopolitan city, which would include but will not be limited to the following topics:

- language policies and natural language protection;

- relationship between minority languages and official languages;

- the survival of minority languages in a cosmopolitan space. 


\section{References}

Backhaus, P. 2006. "Multilingualism in Tokyo: a look into the linguistic landscape". In: Gorter, D. (ed.). Linguistic landscape: a new approach to multilingualism. Clevedon: Multilingual Matters, Ltd. 52-66

Beck, U. and N. Sznaider. 2006. "Unpacking cosmopolitanism for the social sciences: a research agenda”. British Journal of Sociology. 57. 1-23.

Ben-Rafael, E., Shohamy, E., Amara, M.H. and N. Trumper-Hecht. 2006. "Linguistic landscape as symbolic construction of the public space: the case of Israel". In: Gorter, D. (ed.). Linguistic landscape: a new approach to multilingualism. Clevedon: Multilingual Matters, Ltd. 7-30.

Ben-Rafael, E. 2009. "A sociological approach to the study of linguistic landscapes”. In: Shohamy, E. and D. Gorter (eds.). Linguistic landscape: expanding the scenery. New York: Routledge. 40-54.

Cenoz, J. and D. Gorter. 2006. "Linguistic landscape and minority languages". In: Gorter, D. (ed.). Linguistic landscape: a new approach to multilingualism. Clevedon: Multilingual Matters. 67-80.

Göktürk, D., Gramling, D. and A. Kaes (eds.). 2007. Germany in transit: nation and migration 19552005. Berkeley: Univeristy of California Press.

Grześkowiak, M. 2010. Trans-city or inter-city? The co-existance of majority and minority languages in the urban space: a comparative case study of London and Warsaw linguistic landscapes. Poznań: Katedra Ekokomunikacji UAM.

Hornberger, N. 2003. "English in the global ecology of languages: the value of multilingualism". BESIG Business Issues 2. 2-6.

House, J. 2003. "English as a lingua franca: a threat to multilingualism?" Journal of Sociolinguistics. 7.4. 556-578.

Papen, U. 2012. "Commercial discourses, gentrification and citizens' protest: the linguistic landscape of Prenzlauer Berg, Berlin". Journal of Sociolinguistics 16.1. 56-81.

Pavlenko, A. 2009. "Language conflict in Post-Soviet linguistic landscapes". Journal of Slavic Linguistics $17.1-2.247-274$.

Puppel, S. 2007. "Interlingwalizm czy translingwalizm? Interkomunikacja czy transkomunikacja? Uwagi w kontekście wspótistnienia języków naturalnych w ramach globalnej wspólnoty kulturowojęzykowo-komunikacyjnej”. In: Puppel, S. (ed.). Społeczeństwo - kultura - język. Poznań: Katedra Ekokomunikacji UAM. 86-108.

Sandercock, L. 2003. Cosmopolis II. Mongrel cities of the 21st century. London and New York: Continuum.

Shohamy, E. and S. Waksman. 2009. "Linguistic landscape as an ecological arena: modalities, meanings, negotiations, education”. In: Shohamy, E. and D. Gorter (eds.). Linguistic landscape: expanding the scenery. New York: Routledge. 313-331.

Spolsky, B. and R.L. Cooper. 1991. The languages of Jerusalem. New York: Oxford University Press.

Spolsky, B. 2009. "Progelomena to a sociolinguistic theory of public signage". In: Shohamy, E. and D. Gorter (eds.). Linguistic landscape: expanding the scenery. New York: Routledge. 25-39. 